\title{
Transportation proposal for sustainable development integrated with the corridor of the Nile Valley in Egypt
}

\author{
H. El Shimy \\ Architectural Department, Pharos University, Alexandria, Egypt
}

\begin{abstract}
Sustainable development of national schemes requires knowledge of natural, environmental, economic and social resources. It also requires identifying the mutual influences between these resources to achieve the equation of the interaction, producing the sustainable development of nationalism, transportation hubs of national associations and the piercing of the region's planning for the country. One of the means used and the research's aims is to identify the criteria needed to determine the best course for these axes so as to achieve the best performance and lowest cost in the construction phase and sustainable development at start up and in post-construction.

This theory has been applied to the axis of development and reconstruction through the penetration of the Western Desert in order to transfer a lifeline to it. A new approach to a sustainable and integrated development with the artery of the Nile in Egypt was also suggested. This approach provides opportunities for development on the western side of Egypt. It also gives balance and harmony in the geographic distribution of development from east to west along the centre of development on the northern coast and parallel to the Nile Valley using the diagrams of geological and geographic analysis for the planned regions in Egypt.

A set of results can be concluded from this search and the most important is that the priorities are to provide arteries for national transportation, being an ideal solution for sustainable development of national plans in the long run to achieve future sustainable development in Egypt. The area between the axis of development and the Nile River valley is the first fruit of the project.

There is also a set of conclusions, the most important being that whenever the axis penetrates more than one region, it gives an advantage which is the diversity of resources to achieve integration between the regions. Given that
\end{abstract}


interdependence and integration of sustainable development fosters the geographical and arterial corridor it is necessary to link the horizontal so as to create spaces commensurate with the stages of national sustainable development.

It is recommended that research should be the actual implementation of this theme appearing in a phased manner from north to south, and the need for political and legislative support necessary for implementation.

Keywords: sustainable development, transportation, national planning, the corridor of development and reconstruction.

\section{Introduction}

National sustainable development emerged in 1987 and was adopted by the World Commission for Environment and Development. It is defined as a development that has the ability to confirm the needs of future generations without encroaching on their ability to meet their own needs [1].

There are two major trends for sustainable development:

a) Attention to current needs.

b) Conservation of natural resources to meet future needs.

Sustainable development is the process of measuring and assessing the situation as well as the environmental, social and economic variables [2].

\section{Objectives}

a) Draw a map of sustainable urban development in Egypt to strike a balance between the future needs of the population and available natural resources.

b) Social objectives on a regional and provincial planning level in Egypt represented in the economic development through the available projects along the axis of development and reconstruction.

c) Creating social mobility through the increase expected in the population's income which will lead to a boom at a social and economic level.

d) Distribution of the growing need over the original areas of development (the Nile Delta - along the path of the River Nile), and areas along the proposed development and reconstruction axis.

e) Economic regional goals represented in increasing the opportunities of urban development along the development and reconstruction axis.

f) Increasing employment opportunities through agricultural, industrial and commercial projects along the development and reconstruction axis.

g) Rehabilitation of the small towns which are adjacent to the vicinity of the development and reconstruction axis through the presence of urban extension that allows the absorption of urban development, industrial and agricultural projects.

h) Increasing the national income of all society strata.

i) Redistribution of the population and reduce their centring along the Nile River Delta from the rate of $5 \%$ to $30 \%$ of the total area of Egypt. 


\section{Determinants for the sustainability of national development}

Achieving sustainable national development requires the interaction of the systems of the biosphere, social and technological environments. Achieving sustainable urbanization depends on the knowledge of the citizens' need for a place that provides a decent social life and the targeted economic level [3].

In order to support sustainable development projects, it is required to develop a geographical information system to identify priorities for development in the urban corridor. The attached figure shows the system information for achieving sustainability (fig. 1).

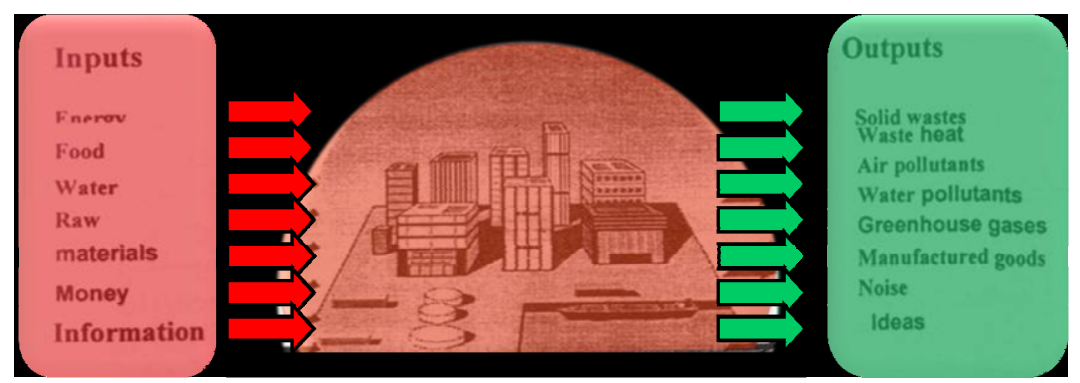

Figure 1: $\quad$ Inputs and outputs of sustainable development [4].

\section{Mechanisms for selecting the axis of transportation for sustainable development}

In order for the mechanism of selecting the axis of transportation for national sustainable development to be achieved, it requires the provision of a set of exploratory stages for spatial environment of the project. These stages consist of:

- Land Cover

- Geology of the Earth

- Urbanism
- Land owner

-Topographic

- Underground water

- Services

The transportation hubs are considered one of the most important foundations upon which civilizations are built; especially considering that Egypt has a historical precedent represented in the facility of water; the Nile River, which facilitates the movement from south to north with the current and vice versa with the wind. With the expected increase in the number of people, we find that the current transportation does not meet the needs of the future that opens new horizons for urban, industrial, agricultural, trade and tourism expansion. We find that the required axis that supports development is the one that is parallel to the axis of the Nile River which leads to a parallel longitudinal development from north to south. 


\section{International experiments for developmental intellect; the axes and sustainable development corridor and its objectives}

There were many development and reconstruction projects in different countries which differed according to development intellect and its objectives.

\subsection{Development corridor project (Tanzania - Kenya - Uganda) [5]}

This project was established in order to bring national economic development to attract agricultural, industrial and tourist investments.

The overall objective of the project is to define a least cost expansion plan with a 20-year planning horizon for the power generation systems of Kenya, Tanzania and Uganda. In order to achieve this, the client appointed Scott Wilson to carry out a study to establish the existing and future demand--supply balance, evaluate the existing and committed generation and transmission system, and determine the least cost means of expanding the power system to meet the demand growth of the three countries and strengthen the interconnection links.

\subsection{Development corridor project in Kuwait: development bridge [6]}

This project was proposed to bring about urban development along the axis that serves all parts of the Arabian Gulf and includes entertainment, financial and sports projects.

\subsection{Development corridor project in the state of Virginia [7]}

The basic idea of this project depends on linking reconstruction in the American states surrounding Virginia.

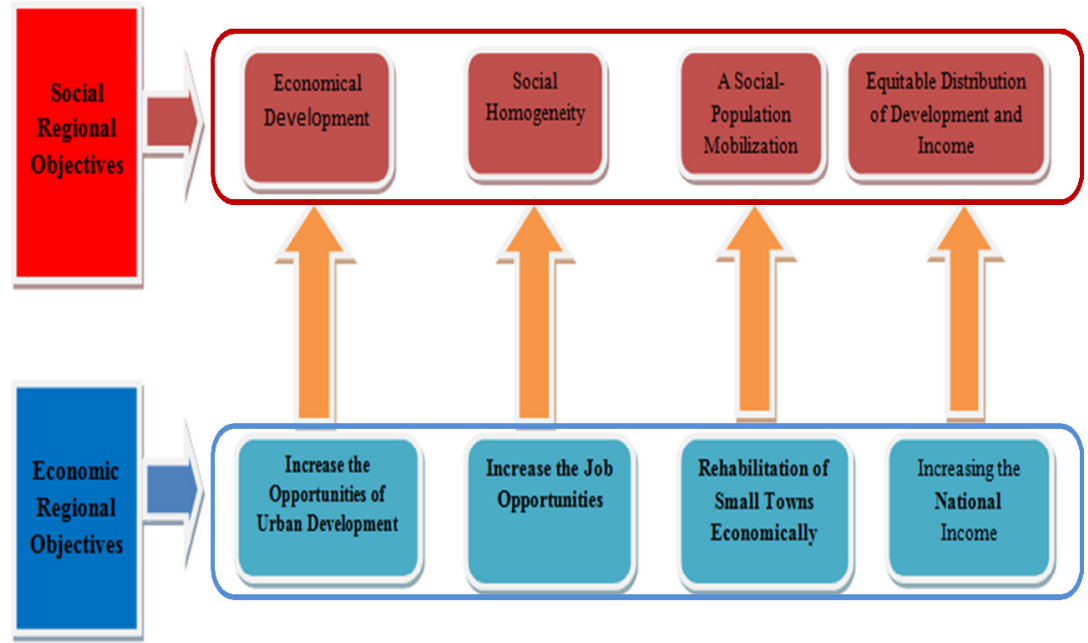

Figure 2: $\quad$ Objectives of urban development in the national corridor [8]. 


\section{General approach to the development and reconstruction corridor in Egypt [9]}

The development and reconstruction corridor proposal includes five major components which are:

Longitudinal axis for the highway according to international specifications. This way begins near El Alamein and continues until the southern borders of Egypt with a length of $1.2 \mathrm{~km}$.

Twelve axes of transverse roads linking the main road to the main population centres along its route length of $1.2 \mathrm{~km}$.

A railway for express transportation parallel to the main road.

Water pipe from Lake Nasser south until the end of the road on the Mediterranean coast. This pipe is for human use along the longitudinal axis.

Power line to provide energy in the project's initial stages until facilitating renewable energy sources for future projects.

\section{Levels of analysis for development map for development and reconstructions corridor}

Putting a development map for a reconstruction and development corridor requires knowledge of urban and economic dimensions to determine the validity and priorities of development areas along the corridor. It is based on a residential areas database and linkage between the current urban pattern and the new urban communities, which are divided into three categories:

First category: Map of Development and Reconstruction of the Republic.

Second category: Regional Maps of Regions and Governorates.

Third category: General and Strategic Schemes for cities.

\section{Why the development and reconstruction corridor in Egypt? [9]}

The development corridor project is one of the most important projects that the country seeks to institutionalize for the following reasons:

Reduce encroachment on agricultural land in the Nile Valley from both the private and government sectors.

a) Reduce encroachment on agricultural land in the Nile Valley from both the private and government sectors.

b) Opening up new urban areas near places of demographic composition.

c) Development of several areas for land reclamation in the Western Delta and the Nile Valley.

d) Providing hundreds of thousands of jobs opportunities in the fields of agriculture, industry, trade and reconstruction.

e) Developing new sites for tourism and relaxation in Western Desert, adjacent to the Nile. 
f) Reducing congestion in the transportation and expanding the network of existing roads.

g) Rehabilitation of a quiet and comfortable life in a clean environment that allows for some creativity at work.

h) Connecting Toshka, east of Owainat and the rest of the New Valley oases to the different areas of the country through a quick and safe means.

i) Creating new opportunities for small investors to gain from projects in different fields.

j) Participation of a wide range of people in development projects, which develops a sense of loyalty and belonging.

k) Opening new horizons to work and enjoy the fruits of achievement in a national project.

j) Creating hope to the youth of Egypt to secure a better future.

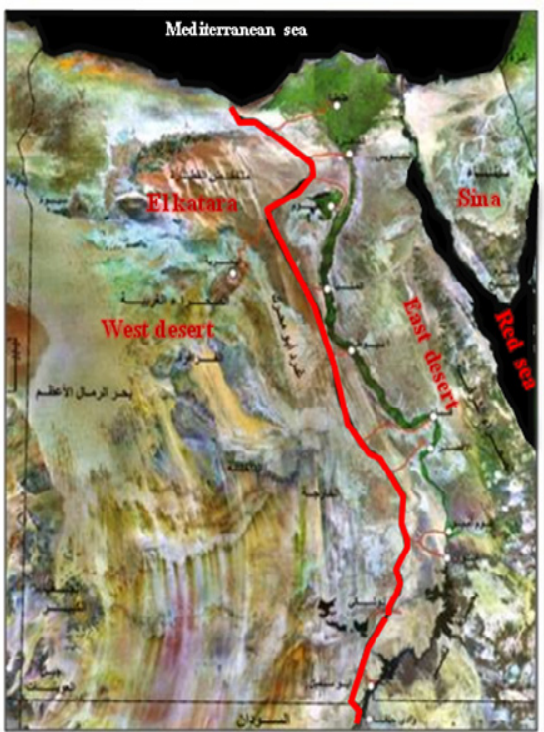

Satellite image of urban and development passage

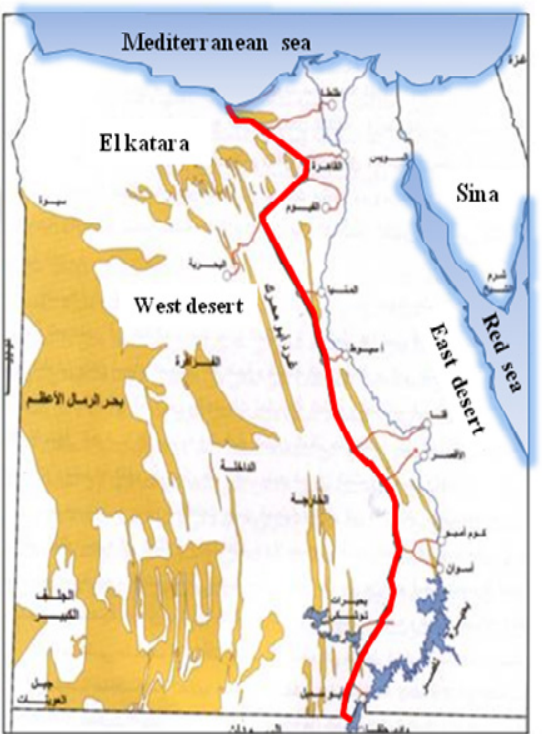

Map of urban and development passage

Figure 3: Urban and development corridor.

\section{Analytical survey of the partial transverse axes of the development and reconstruction corridor}

Analytical survey of the transverse axes is based on a study of all the exploratory stages of each region according to a scientific analytical method that depends on maps and data. 


\subsection{Axis of Alexandria}

a) Parallel to the sea coast providing tourism development and the development of fishery resources and fruit cultivation.

b) Availability of land that is suitable for agriculture in the Western Desert on a geological level.

c) There is the low plains region which supports agriculture, especially in the eastern region.

d) There is a range of groundwater wells in the Western Desert.

e) Urbanization is centred in the north side where the city of Alexandria exists.

f) Matrouh is on the coastline.

g) Services are associated with urbanism and its location.

h) Topography of the land surrounding the axis is low, around 20-25 $\mathrm{m}$ above sea level.

i) The geological nature of the land is undifferentiated Quaternary deposits.

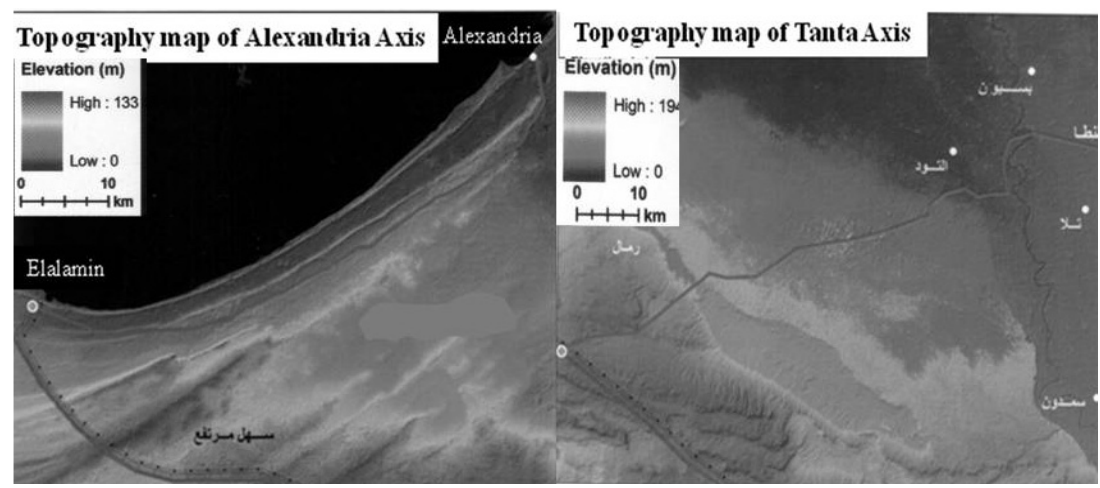

Figure 4: $\quad$ Topography map of Alexandria Axis and Tanta Axis.

\subsection{Axis of Tanta}

Tanta is located on the Nile Delta landfill and is considered a centre for local roads that branch off from it. The proposed axis extends west to the Western Desert to reduce congestion on the agricultural land since it is one of the most congestion cities of the Delta.

\subsection{Axis of Cairo}

This is a vital axis because of the possibility of linking it to the Cairo-Alexandria Desert road; especially considering that Cairo is one of the largest communities in Africa 


\subsection{Axis of Fayoum}

The axis extends from the south-east and extends north to the north-east. It is a unique axis as it is surrounded by landscapes and green areas.

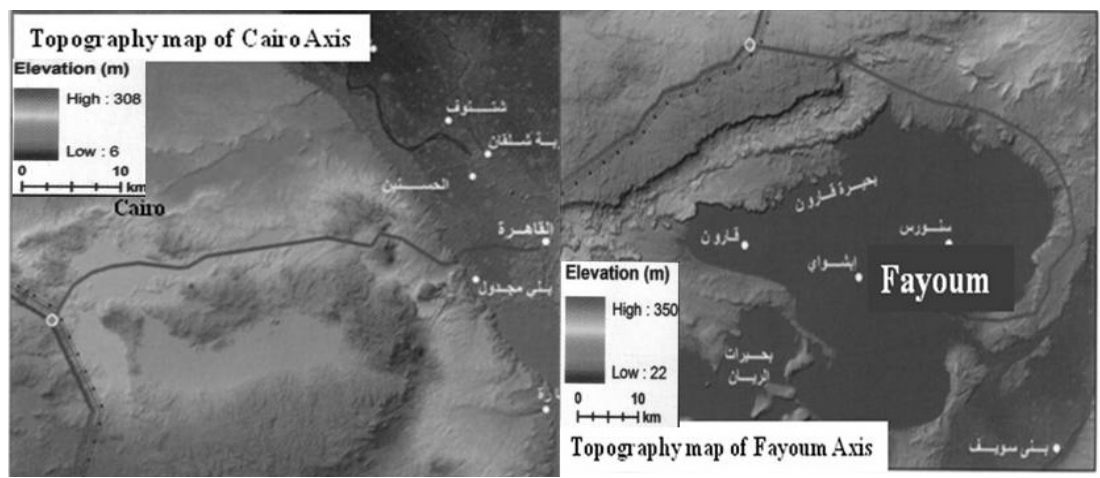

Figure 5: Topography map of Elbahry Axis and the Axis of Al-Minya.

\subsection{Elbahry Axis}

This axis is important because it links the Marine oases to the fabric of the proposed urban development which allows linking to Siwa oasis in the north. This area is considered a fertile land in this region for the cultivation of wheat and palm. Also, weeds spread in this area which allows livestock.

\subsection{Axis of Al-Minya}

Minya Axis is one of the shortest axes that lead to the development and reconstruction corridor. It extends within the area of sand dunes, allowing the existence of agricultural development on the northern side. Services are found at the beginning of the axis by Al-Minya Governorate.

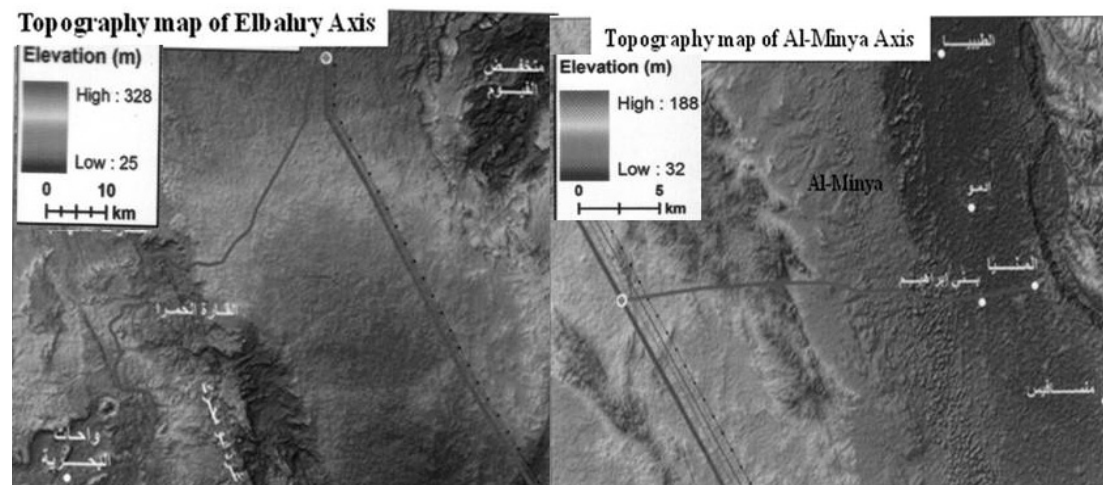

Figure 6: Topography map of the Axis of Assiut and Axis of Qena. 


\subsection{Axis of Assiut}

The proposed axis extends West Assiut in the Nile Valley plain until the flat plateau of the Western Desert.

\subsection{Axis of Qena}

This axis extends by the Nile River breaking into the sand dunes area.

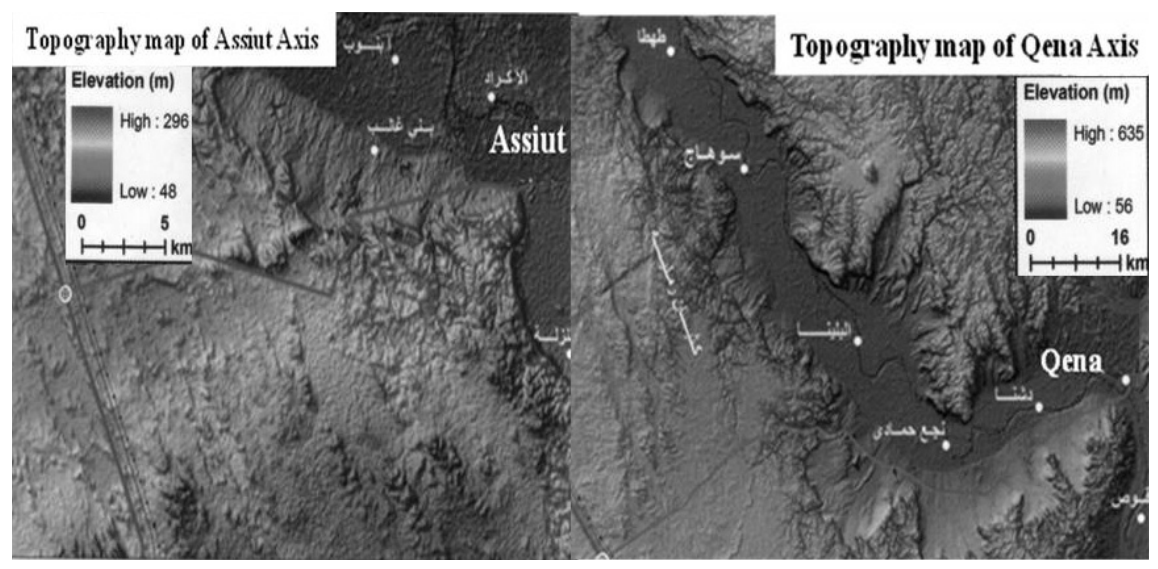

Figure 7: Topography map of the Axis of Assiut and Axis of Qena.

\subsection{Axis of Luxor}

This axis is located in the northeast and is intended to support tourism development which opens new horizons in support of the tourism sector.

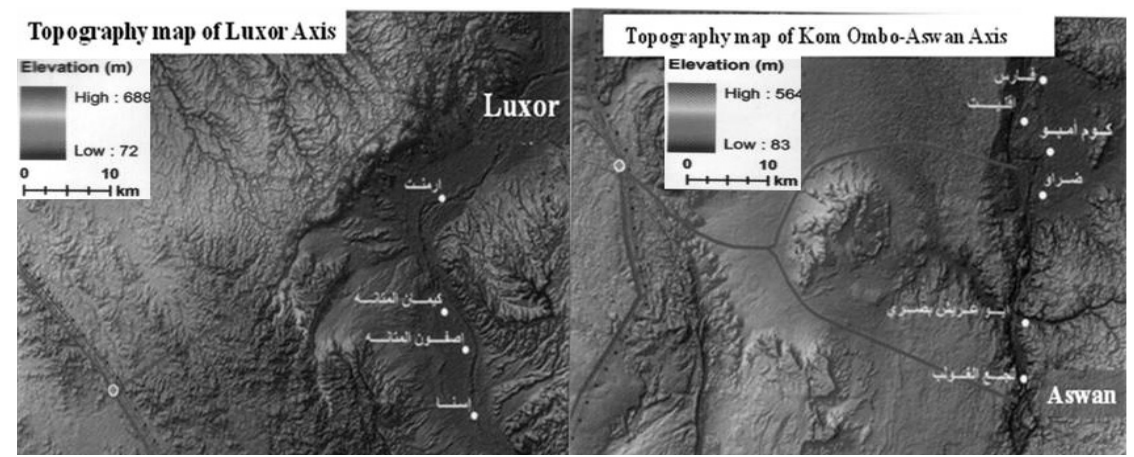

Figure 8: Topography map of the Axis of Luxor and Kom Ombo-Aswan Axis. 


\subsection{Kom Ombo-Aswan Axis}

The Kom Ombo-Aswan Axis a dual axis since it starts by Kom Ombo in the north and Aswan in the south, joins at a single point and then moves in one direction towards the development and reconstruction corridor.

\subsection{Toshka Axis}

The suggested Toshka Axis is considered a vital one that supports the National Toshka project as it provides a means for transporting personnel working in the project to the centres of congestion of population in the North.

\subsection{Axis of Abu Simbel-Lake Nasser}

This axis extends between two points; the first is Lake Nasser in the north where it converges with Abu Simbel in the south until the development corridor. Its beginning is considered vital because of the spread of agriculture and sources of fish wealth

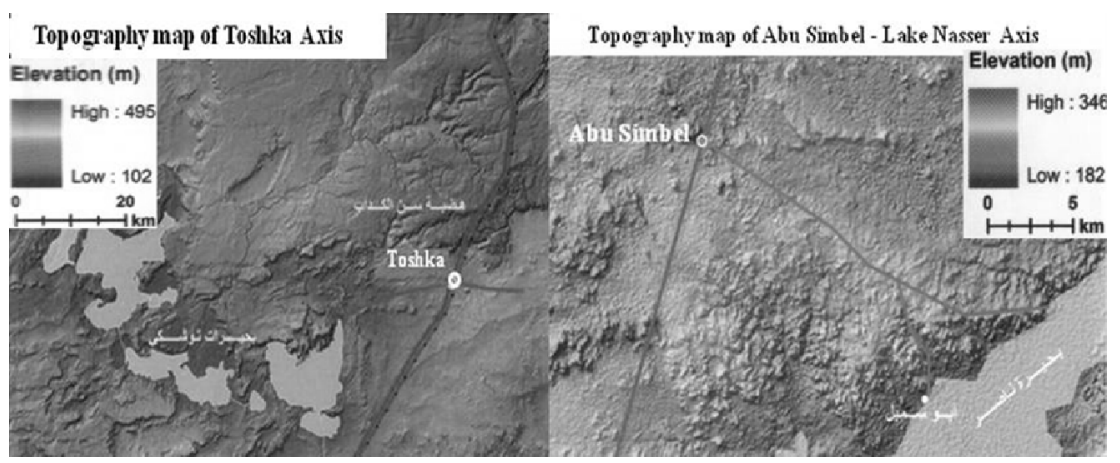

Figure 9: Topography map of Toshka Axis and the Axis of Abu SimbelLake Nasser.

\section{Detailed analysis using SWOT analysis for the development and construction corridor project}

The detailed general analysis using SWOT (Strengths, Weaknesses, Opportunities, and Threats) of the development and construction corridor project depends on knowing the strengths and weaknesses of the project as well as understanding the risks and the overall objectives of the project.

The main points of SWOT analysis are:

- People are not excited about or interested in moving to the new urban areas.

- The lack of a social homogeneity among the displaced population and the indigenous ones. 
- Social development for Tanta Axis in order to reduce congestion in Tanta governorate.

- Establishing urban communities along the Axis of Kom Ombo-Aswan to bring about social development.

- Bringing about urban development in Toshka.

- Tourism development in the Luxor and Abu Simbel Axis.

\section{Results and recommendations}

\subsection{Results}

1. Tourism development is the best method used in dealing with the historical heritage tourism areas.

2. Most international experience of the development corridors of the world depends on the relationship between the progress of development plan with the rates of implementation, including development occurs in parallel way with the implementation rates.

3. Project site for development and reconstruction of the best strategic locations in Egypt, including linking the development between the north and south. 4. Link the new urban communities to the centre of development and reconstruction of the provincial census to enumerate parallel to the River Nile, including a balance in population distribution in Egypt.

5. Islands located north of the axis and the islands south of the axis could cause the development of tourism in Egypt, the islands East region is characterized by industrial and agricultural development.

6. Draft the centre of development and reconstruction allows the absorption of human density, estimated at 10 million people and allow, with 2 million jobs sectors of industry and agriculture.

\subsection{Recommendations}

1. Create an investment fund to finance the centre of development and reconstruction, including funding supports for the security of the project.

2. Implementation of the project should be done at rates that create new urban communities along the axis starting from the corridor-off wheel and then link the vertical axis.

3. Create a map of the combined service and development projects along the corridor development to make a thread and a functional integral.

4. Encourage internal migration from the valley to the corridor development and reconstruction progress to make a dump of population density and the provision of permanent human force along the corridor of development and reconstruction. 5. Connecting waterways to the intersection points of wheel corridor-off of the axis of development and reconstruction with the longitudinal axis of the corridor development. 
6. Create a set of laws and legislation encouraging private investors to establish projects and taxes due on what is considered stimulating factors.

7. Encourage a policy of land ownership for a young colony to set up communities along the corridor of development and reconstruction.

\section{References}

[1] William, S., Elizabeth, E. \& Jenks, M., Achieving Sustainable Urban Form, E \& FN Spon., NY, USA, 200.

[2] Kammeier, H., A strategy for sustainable development of the country, Bangkok, 2002.

[3] Kelly, R., Place Matters. Departmental Communities of local Government, UK, 2007.

[4] Eric, L., Planning for the south west corridor 2020, Government of Western Australia PSM, Planning and infrastructure Dept., Australia, 2009.

[5] Jones, C., Tanga Development Corridor (TDC), Swedish Impact Assessment conference, Uppala, 2007.

[6] http://www.qnaol,net?QNAA r/news bulletin ?Economics (4/2009).

[7] James H. Lambert, Alexander S. Linthicium, and Mathen Jschrosder, Riskbased Prioritization of Transportation Corridors Vulnerable to Development, Center for Risk Management of Engineering System, University of Virginia, 2008.

[8] Magady, S., Development Corridor between Society needs and future vision, towards a new architectural vision: Presentation and Representation, Fifth International Conference, Cairo University, 2009.

[9] El-Baz, F., Development corridor: securing a better future for Egypt, El-AIN Publishing House, Cairo, 2007. 